\title{
Review Artikel : Aktivitas Antikanker dari Spons Laut Genus Xestospongia
}

\author{
Adryan Fristiohady $^{1}$, Prahedi Setya Ibrahim ${ }^{1}$, Asniar Pascayantri ${ }^{1}$ \\ ${ }^{1}$ Jurusan Farmasi, Fakultas Farmasi, Universitas Halu Oleo, Kendari, Indonesia.
}

Email: adryanfristiohady@uho.ac.id

\begin{abstract}
The discovery of novel agents in the treatment of cancer is still being conducted, one of them is by developing the marine natural resources as an anti-cancer drug. Sponges like the genus Xestospongia, are natural marine resources that have potential as anti-cancer. Thus,, this review aims to showing the potential of the genus Xestospongia as an anticancer. This review was carried out by collecting the literature from various databases from 2014 to 2019. Results obtained that marin sponge Xestospongia, including Xestospongia testudinaria, Xestospongia exigua, Xestospongia muta and Xestospongiawiedemayeri, were used as anticancer. These compounds such as Quinolizidine, Aragusterol, Araguspic and many more.
\end{abstract}

Keywords-Xestospongia, anticancer, cytotoxicity

\begin{abstract}
Abstrak
Penemuan obat baru dalam pengobatan kanker masih intensif dilakukan, salah satunya dengan pengembangan sumber daya alam laut sebagai obat anti kanker. Spons seperti genus Xestospongia, merupakan sumber daya alam laut yang memiliki potensi sebagai anti kanker. Oleh karena itu, review ini bertujuan untuk menunjukkan potensispons genus Xestospongia sebagai antikanker. Review ini dilakukan dengan mengumpulkan pustaka dari berbagai database dari tahun 2014 hingga 2019. Hasil yang didapatkan bahwa spesies dari Xestospongia seperti Xestospongia testudinaria, Xestospongia exigua, Xestospongia muta dan Xestospongia wiedemayeri tercatat berpotensi sebagai antikanker. Senyawa-senyawa tersebut seperti Quinolizidine, Aragusterol, Araguspic dan masih banyak lagi.
\end{abstract}

Kata Kunci-Xestospongia, antikanker, sitotoksisitas

\section{PENDAHULUAN}

Di tahun 2018, kanker merupakan penyebab kematian pada lebih dari 65.000 dengan kanker paru dan payudara yang paling sering terdiagnosis hampir ditiap negara di dunia (Khalifa et al., 2019). Di Indonesia itu sendiri di tahun 2018, terdapat total kasus kanker sebesar 348.809 jiwa dengan total kematian yaitu sebesar 207.210 jiwa. Urutan teratas yakni kanker payudara dengan angka kejadian kanker sebesar $16,7 \%$ dan angka kematian sebesar $11,0 \%$, sementara kanker paru masuk dalam urutan ke-6 dengan angka kejadian kanker sebesar 8,6\% dan angka kematian sebesar $12,6 \%$ (Cancer Country Profile, 2020).

Adanya pembatasan dalam penggunaan agen kemoterapi dalam mengatasi kanker yang diakibatkan oleh tingginya tingkat toksisitas dan resistensi tumor terhadap obat kemoterapi setelah terapi lanjutan masih tidak dapat dihindari. Oleh karena itu, sangat penting untuk terus mencari obat baruyang meningkatkan atau mempertahankan kemanjuran, sekaligus meminimalkan toksisitas dan menunda pengembangan resistensi obat. Salah satu alternatif adalah dengan pencarian senyawa obat baru yang berasal dari spons (Tun et al., 2019).
Tercatat hampir 5000 senyawa telah diisolasi dari spons dan berefek sebagai antikanker (Swantara et al., 2019). Salah satu jenis spons yang berpotensi sebagai sumber dari senyawa yang bersifat antikanker adalah spons yang berasal dari genus Xestospongia. Sehingga review ini menyajikan beberapa bukti potensi antikanker spons genus Xestospongia beserta penjelasan tambahan mengenai bahan aktif yang berpotensisebagai antikanker tersebut.

\section{METODE PENELITIAN}

Informasi yang dijadikan data dalam penulisan review jurnal ini dikumpulkan menggunakan metode studi pustaka. Pencarian pustaka dilakukan menggunakan instrumen pencarian berbasis online seperti NCBIPubMed, Google Scholar, dan Elsevier. Kata kunci yang digunakan untuk penelusuran pustaka terkait dengan "Xestospongia" dan "anticancer of Xestospongia". Pustaka yang sudah didapat kemudian dikumpulkan informasi yang diperlukan, disusun sesuai kerangka, data spons genus Xestospongia dengan aktivitas antikanker disusun dalam bentuk tabel, dan penulisan review jurnaldilakukansesuai format yang diberikan. Dari hasil studi literatur diperoleh 27 jurnal terbitan 
2014 - 2020 yang memuat informasi mengenai spons laut genus Xestospongia dengan aktivitas antikanker yang akan ditampilkan pada tabel 1.

\section{HASIL DAN PEMBAHASAN}

\section{A. Potensi spons sebagai antikanker}

Spons berpotensi sebagai antikanker dengan berbagai macam mekanisme yaitu proapoptosis atau menginduksi apoptosis, anti-inflamasi, anti-metastasis, sitotoksik, dan sebagai antioksidan (Calcabrini et al., 2017; Trianto et al., 2016).

Salah satu jenis spons yang bermanfaat dan banyak diteliti terkait potensinya sebagai antikanker adalah spons yang berasal dari genus Xestospongia. Berikut merupakan kandungan metabolit yang terkandung di dalam genus ini yang berpotensi sebagai antikanker (tabel 1).

Tabel I. Aktivitas antikanker dari genus xestospongia

\begin{tabular}{|c|c|c|c|c|}
\hline $\begin{array}{l}\mathbf{N} \\
\mathbf{0}\end{array}$ & $\begin{array}{l}\text { Spesies } \\
\text { Spons }\end{array}$ & Metabolit & $\begin{array}{l}\text { Aktivitas } \\
\text { Antikan } \\
\text { ker } \\
\text { (Lini sel) }\end{array}$ & Sumber \\
\hline \multirow[t]{2}{*}{1.} & $\begin{array}{l}\text { Xestospo } \\
\text { ngia } \\
\text { testudina } \\
\text { ria }\end{array}$ & $\begin{array}{l}\text { 1. Sapi } \\
\text { nofuranone } \\
\text { 2. asam } \\
\text { xestospongic } \\
\text { 3. 24- } \\
\text { hydroperoxy } \\
-24 \text {-vinyl- } \\
\text { kolestero } \\
\text { 4. Sarin } \\
\text { gosterol 29- } \\
\text { hydroperoxy } \\
\text { stigmasta- } \\
5,24-\text { dien- } \\
3 \beta-\text { ol }\end{array}$ & $\begin{array}{l}1 . \quad \mathrm{S} \\
\text { eviks } \\
\text { Cancer } \\
\text { (HeLa) } \\
\text { 2. } \mathrm{H} \\
\text { epar } \\
\text { Cancer } \\
\text { (HepG- } \\
\text { 2), } \\
\text { 3. K } \\
\text { anker } \\
\text { Otak } \\
\text { (Daoy). }\end{array}$ & $\begin{array}{c}\text { Swantara } \\
\text { et al, } \\
2019 ; \\
\text { El Gamal } \\
\text { et al., } \\
2016 .\end{array}$ \\
\hline & & $\begin{array}{c}\text { Langcosterol } \\
\text { A }\end{array}$ & 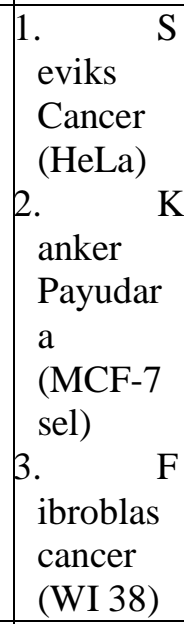 & $\begin{array}{c}\text { Nguyen } e t \\
\text { al., } 2019\end{array}$ \\
\hline 2. & Xestospo & Neo- & Kanker & Hudayah \\
\hline
\end{tabular}

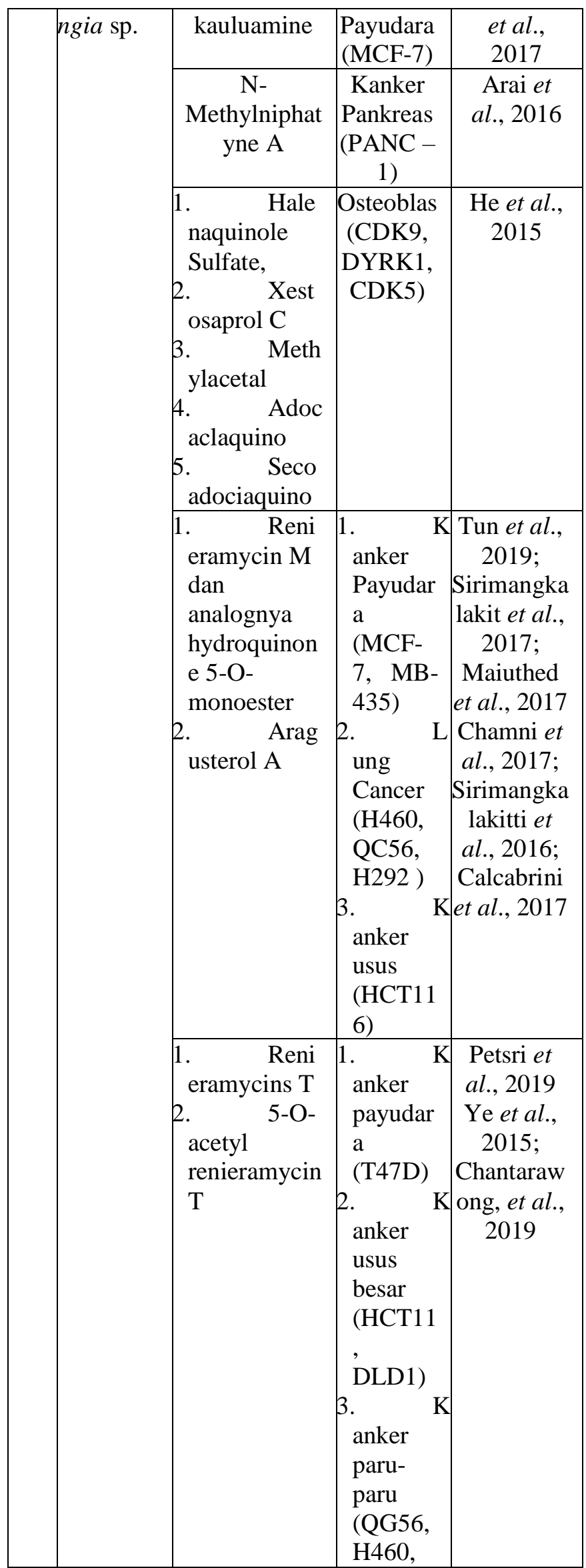




\begin{tabular}{|c|c|c|c|c|c|c|c|}
\hline & $\begin{array}{l}\mathrm{H} 292) \\
\text { anker } \\
\text { pankrea }\end{array}$ & & & & \begin{tabular}{|l} 
A \\
2. Xest \\
obergsterol \\
B
\end{tabular} & & $\begin{array}{c}\text { Kumar, } \\
2020\end{array}$ \\
\hline & \begin{tabular}{|l} 
(AsPC1 \\
) \\
5. $\mathrm{K}$ \\
anker \\
prostat \\
(DU145 \\
)
\end{tabular} & & \multirow[t]{4}{*}{3.} & \multirow[t]{4}{*}{$\begin{array}{l}\text { Xestospo } \\
\text { ngia } \\
\text { exigua }\end{array}$} & \multirow[t]{2}{*}{\begin{tabular}{|cr}
1. & Xest \\
ospongins \\
2. & Xest \\
ospongins B
\end{tabular}} & \multirow{2}{*}{$\begin{array}{l}1 . \quad \mathrm{K} \\
\text { anker } \\
\text { payudar } \\
\text { a (BT- } \\
474) \\
2 . \quad \mathrm{N} \\
\begin{array}{l}\text { eurobla } \\
\text { stom(N } \\
\text { G108- } \\
15)\end{array}\end{array}$} & \multirow{4}{*}{$\begin{array}{c} \\
\\
\\
\text { Aki et al., } \\
2015 \\
\text { Ruocco et } \\
\text { al,2016 }\end{array}$} \\
\hline $\begin{array}{l}\beta \text {-karbolin } \\
\text { chalcones }\end{array}$ & $\begin{array}{c}\text { Kanker } \\
\text { Payudara } \\
\text { (MCF-7) }\end{array}$ & $\begin{array}{l}\text { Reddy } e t \\
\text { al., } 2018\end{array}$ & & & & & \\
\hline $\begin{array}{l}\text { Araguspongi } \\
\text { ne } \mathrm{C}\end{array}$ & \begin{tabular}{|l} 
(MCF-7) \\
Kanker \\
Payudar \\
a (BT- \\
$474)$
\end{tabular} & $\begin{array}{c}\text { Wargaseti } \\
\text { a et al., } \\
\text { 2019; } \\
\text { Zhou et } \\
\text { al., } 2018\end{array}$ & & & $\begin{array}{l}\text { Araguspongi } \\
\text { ne C }\end{array}$ & $\begin{array}{c}\text { Kanker } \\
\text { Payudara } \\
\text { (MDA- } \\
\text { MB-231, } \\
\text { MCF-7 } \\
\text { T-47D, }\end{array}$ & \\
\hline Stigmasterol & Kanker & Nazemi et & & & & HER-2) & \\
\hline & $\begin{array}{l}\text { limfosit } \\
\text { (K562) }\end{array}$ & al., 2020 & 4. & $\begin{array}{l}\text { Xestospo } \\
\text { ngia }\end{array}$ & $\begin{array}{c}\text { Quinolizidin } \\
\mathrm{e}\end{array}$ & $1 . \quad \mathrm{K}$ & $\begin{array}{c}\text { Dung et } \\
\text { al., } 2019\end{array}$ \\
\hline \begin{tabular}{|lr}
1. & Adoc \\
iaquinones \\
AB \\
2. Xest \\
oquinones \\
3. Neoa \\
mphimedne
\end{tabular} & $\begin{array}{c}\text { Kanker } \\
\text { Payudara } \\
\text { (MDA } \\
\text { MB-435, } \\
\text { HCT- } \\
116)\end{array}$ & $\begin{array}{l}\text { Concepci } \\
\text { on } \text { et al., } \\
2014\end{array}$ & & muta & & $\begin{array}{l}\text { Payudar } \\
\text { a } \\
\text { (MCF- } \\
7 \text { ) } \\
\text { 2. K } \\
\text { anker } \\
\text { Hati }\end{array}$ & \\
\hline $\begin{array}{l}\text { Xestoaminol } \\
\text { C }\end{array}$ & 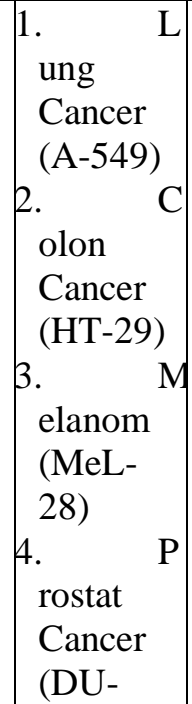 & $\begin{array}{c}\text { Fabišíkov } \\
\text { á et al., } \\
2016\end{array}$ & & & & \begin{tabular}{|l}
\multicolumn{2}{|l}{ (HepG- } \\
2) \\
3. \\
anker \\
Leukim \\
ia (HL- \\
$60)$ \\
4. \\
anker \\
Paru \\
(LU-1) \\
5. \\
anker \\
Kulit \\
(SK- \\
Mel-2)
\end{tabular} & \\
\hline & $\begin{array}{l}\text { 145) } \\
\text { lioma } \\
\text { (SHG- } \\
44)\end{array}$ & & 5. & $\begin{array}{l}\text { Xestospo } \\
\text { ngia } \\
\text { wiedemay } \\
\text { eri }\end{array}$ & $\begin{array}{l}\text { Drimenyl } \\
\text { fenol }\end{array}$ & \begin{tabular}{|ll}
1. & $\mathrm{~K}$ \\
anker & \\
Usus & \\
2. & $\mathrm{~K}$ \\
anker &
\end{tabular} & $\begin{array}{l}\text { Carraso et } \\
\text { al., } 2014\end{array}$ \\
\hline $\begin{array}{l}\text { 1. Xest } \\
\text { obergsterol }\end{array}$ & LTB4 & $\begin{array}{l}\text { Chaudhari } \\
\text { dan }\end{array}$ & & & & \begin{tabular}{|l|} 
Payudar \\
a
\end{tabular} & \\
\hline
\end{tabular}




\section{B. Potensi antikanker spons genus xestospongia}

\section{Xestospongia testudinaria}

Xestospongia testudinaria menjadi sumber alkaloid indol, sterol, sterolester, dan asam lemak tak jenuh (El Gamal et al., 2016).

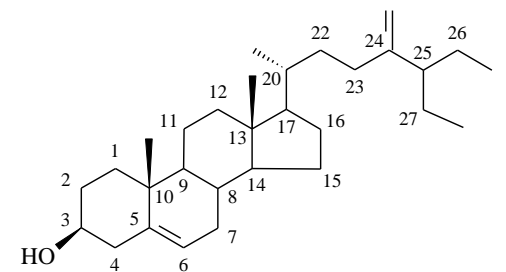

(a)

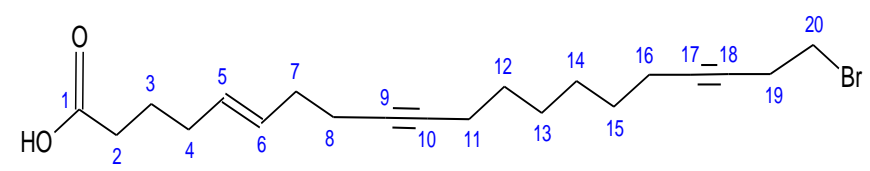

(c)

Gambar 1. struktur senyawa sterol (a) alkaloid (b) dan asam lemak tak jenuh(c) (El Gamal et al., 2016)

Ekstrak metanol X. Testudinaria dari Baliberpotensi antikanker terhadap sel HeLadengan IC50 yakni 1327 ppm serta LC50 yaitu 31,62 ppm (toksik). Ekstrak kloroformnya adalah yang paling toksik dengan Nilai LC50 39,81 ppm. Fraksi yang paling beracun dengan LC50 yaitu 44,67 ppm $(<1000$ ppm, sehingga dilanjutkan ke uji terhadap sel HeLa sebagai uji antikanker) dengan uji MTT(Microtetrazolium) untuk mengukur proliferasi sel berdasarkanpengurangan garam tetrazolium kuning MTT, yang direduksi menjadi kristal formazan ungu oleh mitokondria(Swantara et al., 2019).

Pada penelitian El Gamal (2016), aktivitas antikanker (IC50 $=2,273 \mathrm{ppm})$ dariisolat toksik $\mathrm{X}$. testudinaria denganIC50ekstrak etanolX. testudinaria pada HeLa, HepG-2, dan sel Daoy adalah masing-masing 83,35 ; 23,45 dan 23,31 ppm. Selain itu, n-EH dari sponssama memiliki nilai IC50 33,7 ; 30,2, dan 20,74 ppmmasingmasing di sel HeLa, HepG-2, dan Daoy. Ini bisa menjadi bahan pembanding dalam hal memilih jenis pelarut untuk ekstraksi sampel.

\section{Xestospongia sp.}

Agar lebih jelas beberapa senyawa aktif potensial antikanker dalam pembahasan perpoinXestosposia sp. yakni sebagai berikut :

\subsection{Neo-Kauluamine}

Senyawa Neo-Kauluamine dari ekstrak metanol Xestospongia sp. secara signifikan menghambat pertumbuhan sel MCF-7 konsentrasi $0,391 \mu \mathrm{g} / \mathrm{ml}>24$ jam dan $0,781 \mu \mathrm{g} / \mathrm{ml}>48$ dan 72 jam. Kesimpulan hasil ekstrak menghambat pada $100 \mu \mathrm{g} / \mathrm{ml}$ dengan IC50 yaitu $97,72 \mu \mathrm{g} / \mathrm{ml}$ (72 jam)(Hudayah et al., 2017).

\subsection{Renieramycin $M \quad(R M)$ dan analognya hydroquinone 5-O-monoester}

Renieramycin M (RM) adalah contoh tetrahydroisoquinoline yang distabilikan dengan $\mathrm{KCN}$ murni. Efek kombinasinya dengan DOX pada MCF-7 berefek pada siklus sel, apoptosis, dan transkriptome.Nilai IC50 kombinasi $<1 \mu \mathrm{M}$ menandakan sinergisme, IC50 mendekati 1 nilai menandakan signifikansi, IC50 $>1 \mu$ Mmenandakan antagonisme (Tun et al., 2019)

RM memiliki aktivitas antimetastatik dan menekan sel-sel induk kanker (Maiuthed et al., 2017). IC50 RMyakni $\quad 0,01-0,10 \quad \mu \mathrm{M}$ terhadap sel H460 (Sirimangkalakitti et al., 2017)IC50 $1.1-1.6 \quad \mu \mathrm{M}$ (Sirimangkalakitti et al., 2016) $0,5-2,5 \mu \mathrm{M}$ dalam mengurangi tingkat protein (Calcabrini et al., 2017).

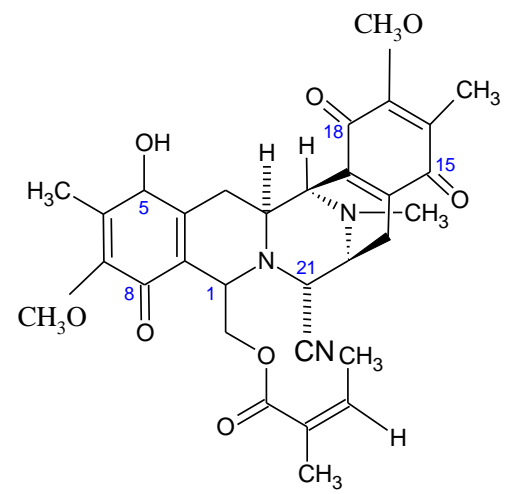

Gambar 2 . Struktur senyawa Renieramycin M (Tun et al., 2019)

Hydroquinone 5-O-monoester analog dari Renieramycin $\mathrm{M}$ memberikan antiproliferatif sekitar 810 kali lipat peningkatan sitotoksisitas terhadap metastasis lini sel H292 (Kanker Paru) (Chamni et al., 2017).

\subsection{Renieramycin $T$}




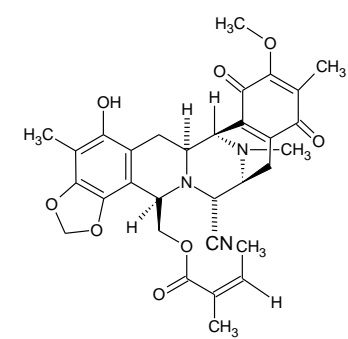

Gambar 3. Struktur senyawa Renieramycin T

(Chantarawong et al.,2019)

Renieramycin $\mathrm{T}$ (RT) memiliki cincin aromatikdengan nilai IC50mulai dari 4,7 hingga $98 \mathrm{nM}$ (Ye et al., 2015). RT dengan menginduksi degradasi Mcl-1 dalam sel kanker paru-paru yang mana waktu paruh Mcl-1 secara dramatis diperpendek (paruh Mcl-1 untuk $1 \mu \mathrm{M}$ RT adalah 1,52 jam dibanding 3,44 jam) kemudian pembentukan kompleks meningkat secara dramatis dan kematian sel dimediasi dengan menargetkan degradasi Mcl-1 (Petsri et al., 2019).

\subsection{5-O-acetyl renieramycin $T$}

Renieramycins A-Y adalah alkaloid tetrahydroisoquinoline. Penambahan asetil dengan esterifikasi gugus fenol menghasilkan 5-O-acetyl renieramycin T. Nilai IC50 kisaran 0,66 $\mu \mathrm{M}$ (H292), 33,24 $\mu \mathrm{M}$ (A549) dan 33,77 $\mu \mathrm{M}$ (H23) dengan cara menginduksi apoptosis, menekan CSC, dan sel H292 yang peka terhadap cisplatin (Chantarawong et al.,2019).

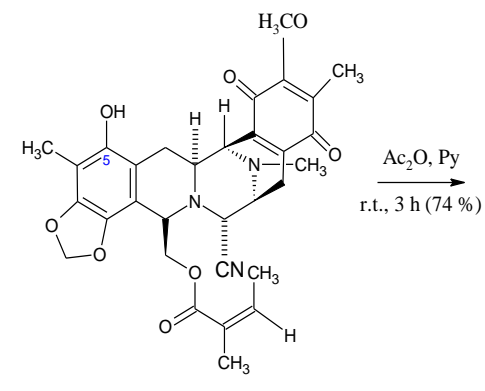

(a)

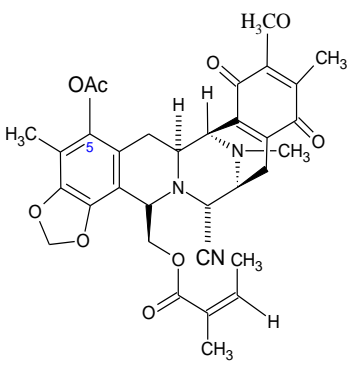

(b)
Gambar 4. Struktur Senyawa Renieramycin T (a) menjadi 5-O Acetyl Renieramycin T (b) (Chantarawong et al.,2019)

\subsection{N-Methylniphatyne A}

Senyawa N-methylniphatyne A dari Xestospongia sp. dengan sistem ujiantikankeryang disesuaikan dengan kebutuhan nutrisi yang memanfaatkan media kultur yang kekurangan glukosa memiliki potensi antikanker dengan nilai IC50 yang dapat dilihat pada tabel 2 .

Tabel II. IC50 N-Methylniphatyne A pada sel PANC1 (Arai et al., 2016)

\begin{tabular}{|l|c|c|}
\hline \multirow{2}{*}{} & \multicolumn{2}{|c|}{ IC50 $(\mu \mathrm{M})$} \\
\cline { 2 - 3 } & Glukosa & Glukosa \\
\hline
\end{tabular}

\begin{tabular}{|c|c|c|}
\hline & $(-)$ & $(+)$ \\
\hline $\begin{array}{c}\text { N-Methylniphatin A } \\
\text { Alami }\end{array}$ & 16 & $>100$ \\
\hline $\begin{array}{c}\text { N-Methylniphatin A } \\
\text { Sintesis }\end{array}$ & 17 & $>100$ \\
\hline Analogue 6 & 18 & $>100$ \\
\hline Analogue 7 & 8,8 & $>100$ \\
\hline
\end{tabular}

Keterangan : Analog $6<$ analog 7 menunjukkan bahwa posisi bagian alkunatidak penting untuk aktivitas sitotoksik

2.6. Halenaquinole sulfate, xestosaprol C methylacetal, adocaclaquinone $B$ dan secoadociaquinone $B$

Adoclquinone B dan Secoadociaquinone B masingmasing menghambatsecara selektif terhadap CDK9/cyclin T (IC50: $3 \mu \mathrm{M}$ ) dan CDK5 / p25 (IC50: 6 $\mu \mathrm{M})$. Haleqanuinol Sulfatemenunjukkanaktivitas yang signifikan terhadap sebagian besar protein kinase mulai dari 0,5 hingga 7,5 $\mu \mathrm{M}$.Sementara Xestoposaprol C Methylacetal menunjukkan aktivitas marginalterhadap DYRK1A $(9,3 \mu \mathrm{M})(\mathrm{He}$ et al., 2015).

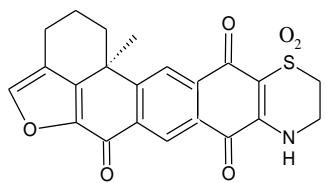

(a)

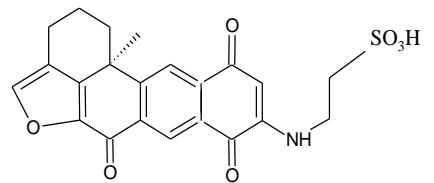

(b)<smiles>C[C@]12CCC(=O)c3coc(c31)C(=O)c1cc3c(O)ccc([N+]([O-])([O-])O[Na])c3cc12</smiles>

(c)<smiles>C[C@]12O[C@@H](O)C3=C1[C@@](C)(CCC(=O)[C@H]3O)c1cc3c(O)ccc(O)c3cc1C2=O</smiles>

(d)
Gambar 5. Struktur senyawa Adoclquinone B (a) Secoadociaquinone B (b)Haleqanuinol sulfate (c) dan Xestoposaprol C methylacetal (d) (He et al., 2015)

\subsection{Araguspongine $\mathrm{C}$}




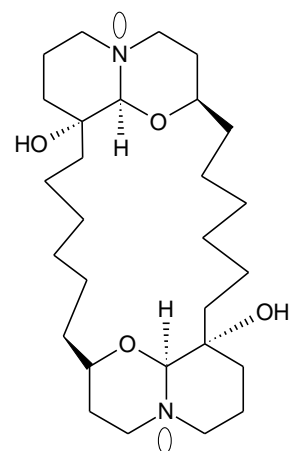

Gambar 6. Struktur Senyawa Araguspongine C (Aki et al., 2015).

Araguspongine Cmerupakan alkaloid tipe macrocyclic oxaquinolizidine dengan potensi autophagic sel BT-474 melalui penekanan $\mathrm{PI} 3 \mathrm{~K} / \mathrm{Akt} /$ pensinyalan mTOR, dari interaksi langsung antara araguspongine $\mathrm{C}$ dan HER2 receptor (Zhou et al., 2018). Ditunjukkan oleh pembentukan autophagosome dan peningkatan regulasi Atg3, Atg7, Atg16L, dan LC3A / B. Araguspongine C juga menghambat proliferasi beberapa lini sel kanker payudara dalam manne tergantung dosis (Wargasetia et al., 2019).

\section{8. $\beta$-Karbolin Chalcones dan Stimasterol}

$\beta$-karbolin chalcones adalah keton aromatikdenganIC50 yaitu 2,25 $\mu \mathrm{M}$ terhadap MCF-7 (Reddy et al., 2018). Sedangkan stigmasterol yang merupakan golongan sterol memiliki IC50 terhadap sel kanker limfosit (K562) yaitu 18/3 hingga $34 / 3 \mu \mathrm{g} / \mathrm{ml}$ (Nazemi et al., 2020).

\subsection{Adociaquinon, neoamphimedin}

xestoquinon

dan

Adociaquinon adalah alkaloid hasil sintesis dari xestoquinon yang menunjukkan IC50 terhadap sel HCT116 masing-masing 24 dan $21 \mu \mathrm{M}$. Neoamphimedin juga alkaloid yang menunjukkan sitotoksisitassignifikan terhadap sel HCT-116 dan sel KB dibandingkan amfimedin. Neoamphimedin sebanding dengan etoposide dalam mengurangi ukuran xenografts tumor dari sel lini kanker HCT-116dan lini sel kanker nasofaring (Concepcion et al., 2014).

\subsection{Aragusterol A}

Aragusterol A adalah steroid untuk menghambat pertumbuhansel kanker yang resistan terhadap cisplatin dan doxorubicin. Misalnya, IC50cisplatin yang resisten adalah $30,3 \mu \mathrm{M}$ (dibandingkan $0,18 \mu \mathrm{M}$ dalam sel yang peka);IC50 aragusterol A adalah $0,18 \mu \mathrm{M}$ (dibandingkan $0,42 \mu \mathrm{M}$ dalam sel yang peka). IC50 doxorubicin dalam sel leukemia resisten terhadap doxorubicin adalah 5,05 $\mu \mathrm{M}$ (dibandingkan $0,10 \mu \mathrm{M}$ dalam sel yang peka);IC50 aragusterol A adalah $0,73 \mu \mathrm{M}$ (dibandingkan $0,12 \mu \mathrm{M}$ dalam sel induknya) (Calcabrini et al., 2017).

\subsection{Xestoaminol C}

Xestoaminol C merupakan amina alkoholyang menunjukkan aktivitas melawan reverse transcriptase dan juga potensi sitotoksik/antiproliferatif yang luar biasa pada beberapa sel kankermanusia seperti A-549, HT-29, MeL-28, DU-145 dan SHG- 44 (Fabišíková et al., 2016).

\subsection{Xestobergsterol A dan xestobergsterol B}

Xestobergsterol A dan xestobergsterol B keduanya ialah golongan sterol yang menghambat fosfolipase A2 dan menghambat mediator inflamasi seperti NF- $\kappa B$. Verifikasi Xestospongia carbonariamemungkinkan sifat sitotoksik. Xestospongia testudinaria menekan produksi mediator leukotriene B4 (LTB4), yang merupakan indikator permeabilitas vaskular(Chaudhari dan Kumar, 2020).

\section{Xestospongia exigua}

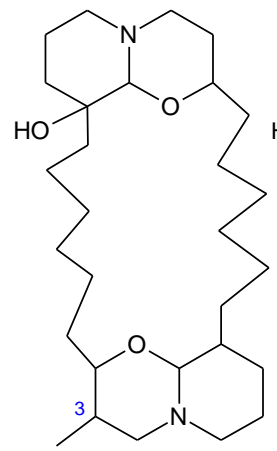

(a)

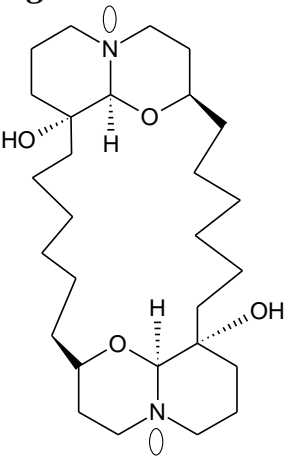

(b)
Gambar 7. Struktur senyawa xestospongins (a) dan araguspongine $\mathrm{C}$ (b)(Aki et al., 2015)

Secara kimia, xestospongins/araguspongine adalah dimeric 2,9-disubstitusi 1-oxaquinolizidines. IC50araguspongine $\mathrm{A}$ dan araguspongine $\mathrm{C}$ terhadap BT-474masing-masing 9,3 dan 15,2 $\mu \mathrm{M}$ (Aki et al., 2015). Xestospongi B menginduksi autophagy melalui inositol triphosphate, antagonistik reseptor pada sel neuroblastoma. Araguspongine $\mathrm{C}$ menghambat proliferasi beberapa lini sel kanker payudara secara in vitro tergantung dosis. Induksi ditandai dengan pembentukan vakuola danupregulation dari penanda autofagy (Ruocco et al,2016).

\section{Xestospongia muta}

Quinolizidine adalah kumpulan alkaloid turunan Llysine. Dibentuk oleh penambahan makrosiklik dua quinolizidine atau 1-oxaquinolizidine moieties, disebut bis-QA menunjukkan potensi seperti sitotoksisitas. 


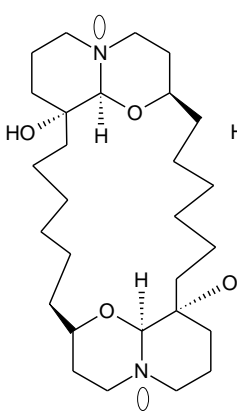

(a)

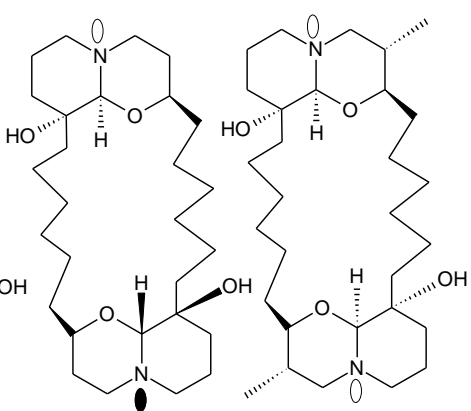

(b) (c)

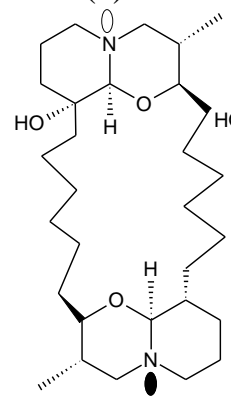

(d)

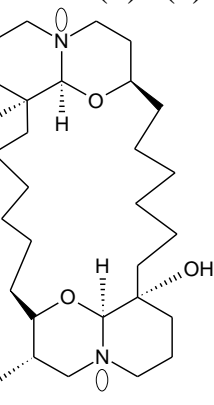

(e)

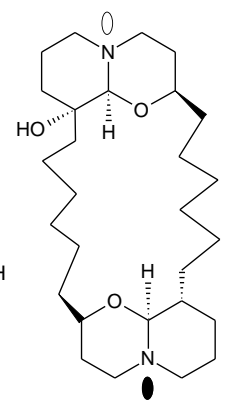

(f)

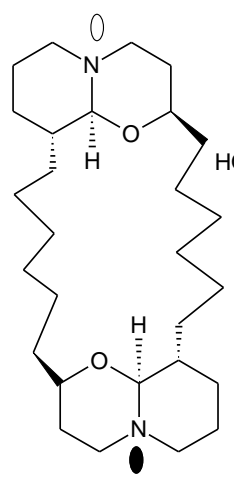

(g)

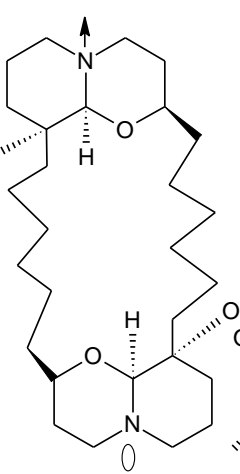

(h)

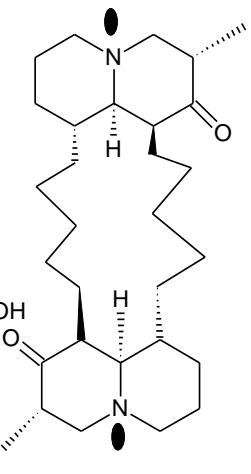

(i)

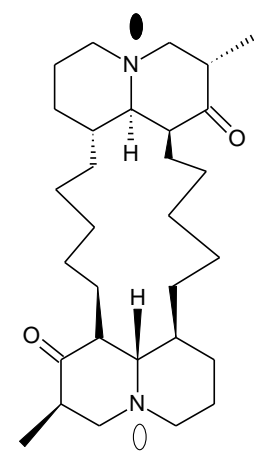

(j)

Gambar 8. Struktur Senyawa araguspongines C(a) meso-araguspongine $\mathrm{C}(\mathrm{b})$ araguspongines N-P (c-e) araguspongine $\mathrm{A}(\mathrm{f})$ araguspongine $\mathrm{E}(\mathrm{g})$ araguspongine (h)petrosin(i) dan petrosin A (j) (Dung et al., 2019)
Tabel III. Ringkasan IC50 tiap bis-QA terhadap beberapa lini sel kanker (Dung et al., 2019)

\begin{tabular}{|c|c|}
\hline Lini Sel & $\begin{array}{c}\text { IC50 }(\mu \mathrm{M}) \\
\text { Rendah }\end{array}$ \\
\hline HepG-2 & 0,43 \\
\hline HL-60 & 0,62 \\
\hline LU-1 & 0,76 \\
\hline MCF-7 & 0,44 \\
\hline SK-Mel2 & 0,77 \\
\hline \multicolumn{2}{|c|}{$\begin{array}{l}\text { Kesimpulan : } \\
\text { NilaiIC50 Tertinggi : petrosin dan petrosin } \mathrm{A} \\
\text { dengan rata-rata }>50 \mu \mathrm{M} \\
\text { Nilai IC50 Terendah : semua dari meso- } \\
\text { araguspongine } \mathrm{C}\end{array}$} \\
\hline
\end{tabular}

\section{Xestospongia wiedemayeri}

Drimenyl fenol merupakan campuran biosintesis (polyketideeterpenoid) yang mengandung unit seskuiterpen yang bergabung dengan fenolik menghambat kolesterol transfer protein (CETP) ester wiedendiol A danwiedendiol B.

Tabel IV. IC50 dari 13 dan 15-Fluorouracil(Carraso et al., 2014).

\begin{tabular}{|c|c|c|c|}
\hline \multirow{4}{*}{$\begin{array}{c}\text { Kanker } \\
\text { Payudara }\end{array}$} & Lini Sel & $\mathbf{1 3}$ & $\mathbf{1 5 - F u}$ \\
\cline { 3 - 4 } & & $\begin{array}{c}\text { IC50 } \\
(\boldsymbol{\mu M})\end{array}$ & $\begin{array}{c}\text { IC50 } \\
(\boldsymbol{\mu M})\end{array}$ \\
\cline { 2 - 4 } & MCF-7 & 0,35 & 2,86 \\
\cline { 2 - 4 } & MDA-MB-231 & 0,46 & 18,12 \\
\cline { 2 - 4 } & $\mathrm{T}-47 \mathrm{D}$ & 0,63 & 10,56 \\
\cline { 2 - 4 } & E0771 & 0,39 & 0,28 \\
\cline { 2 - 4 } & MCF-10A & 3,15 & 8,06 \\
\hline Kanker & T-84 & 0,56 & 3,35 \\
\cline { 2 - 4 } Paru & HT-29 & 1,97 & 2,58 \\
\cline { 2 - 4 } & RKO & 0,59 & 4,39 \\
\cline { 2 - 4 } & SW-480 & 0,92 & 3,69 \\
\cline { 2 - 4 } & CCD18Co & 0,33 & 9,26 \\
\hline
\end{tabular}

\section{KESIMPULAN}

Spons umumnya mengandung komponen utama meliputi alkaloid, sterol, poliketida dan sebagainya yang terus dikembangkan terkhusus genus Xestospongia dengan aktivitas antikanker yang berbeda-beda konsentrasinya begitupun selektivitasnya terhadap lini sel kanker 


\section{DAFTAR PUSTAKA}

Akl, M. R., Ayoub, N. M., Ebrahim, H. Y., Mohyeldin, M. M., Orabi, K. Y., Foudah, A. I., \& Sayed, K. A. E., 2015, Araguspongine C induces autophagic death in breast cancer cells through suppression of c-met and HER2 receptor tyrosine kinase signalling, Marine Drugs, Vol. 13, No.1 : 288-311.doi: https://doi.org/10.3390/md13010288

Arai, M., Kamiya, K., Shin, D., Matsumoto, H., Hisa, T., Setiawan, A., \& Kobayashi, M., 2016, NMethylniphatyne A, A new 3-Alkylpyridine alkaloid as an inhibitor of the cancer cells adapted to nutrient starvation, from an indonesian marine spons of xestospongia sp., Chemical And Pharmaceutical Bulletin, Vol. 64, No.7 : 766-771. doi : 10.1248/cpb.c1600118

Calcabrini, C., Catanzaro, E., Bishayee, A., Turrini, E., \& Fimognari, C., 2017, Marine spons natural products with anticancer potential: an updated review. Marine Drugs, Vol. 15, No.10 : 310. doi : https://doi.org/10.3390/md15100310

Cancer Country Profile, 2020, Burden of cancer indonesia.

https://www.who.int/cancer/country-

profiles/IDN_2020.pdf?ua=1 (diakses 28 Juli 2020)

Carrasco, E., Álvarez, P. J., Melguizo, C., Prados, J., Alvarez-Manzaneda, E., Chahboun, R.,\& Rodriguez-Serrano, F., 2014, Novel merosesquiterpene exerts a potent antitumor activity against breast cancer cells in vitro and in vivo, European Journal Of Medicinal Chemistry, Vol.79 : 1-12. doi https://doi.org/10.1016/j.ejmech.2014.03.071

Chamni, S., Sirimangkalakitti, N., Chanvorachote, P., Saito, N., \& Suwanborirux, K., 2017, Chemistry of renieramycins. 17. a new generation of renieramycins: hydroquinone 5o-monoester analogues of renieramycin $\mathrm{m}$ as potential cytotoxic agents against non-smallcell lung cancer cells. Journal Of Natural Products, Vol.80, No.5 : 1541-1547. doi : https://doi.org/10.1021/acs.jnatprod.7b00068

Chantarawong, W., Chamni, S., Suwanborirux, K., Saito, N., \& Chanvorachote, P., 2019, 5-OAcetyl-Renieramycin $\mathrm{T}$ from blue spons xestospongia sp. induces lung cancer stem cell apoptosis. Marine drugs, Vol.17, No.2 : 109. doi : https://doi.org/10.3390/md17020109
Chaudhari, S., \& Kumar, M. S., 2020, Marine sponss sarcotragus foetidus, xestospongia carbonaria and spongia obscura constituents ameliorate IL $1 \mathrm{~B}$ and IL 6 In lipopolysaccharide induced RAW 264.7 macrophages and carrageenan induced oedema in rats. Cell, Vol.80 : 100, doi : https://doi.org/10.1007/s10787-020 00699-2

Concepcion, G. P., Anas, A. R. J., \& Azcuna, M. A., 2014, Anticancer compounds from philippine marine organisms act on major pathways in cancer. Philippine Science Letters, Vo.7, No.1 : 207-227.

Dung, D. T., Hang, D. T. T., Yen, P. H., Quang, T. H., Nhiem, N. X., Tai, B. H., \& Kiem, P. V., 2019, Macrocyclic bis-quinolizidine alkaloids from xestospongia muta. Natural Product Research, Vol.33, No.3 : 400-406. doi : https://doi.org/10.1080/14786419.2018.145504 3

El-Gamal, A. A., Al-Massarani, S. M., Shaala, L. A., Alahdald, A. M., Al-Said, M. S., Ashour, A. E. \& Youssef, D. T., 2016, Cytotoxic compounds from the saudi red sea spons xestospongia testudinaria. Marine drugs, Vol.14, No.5 : 82 doi : https://doi.org/10.3390/md14050082

Fabišíková, M., Martinková, M., Hirková, S., Gonda, J., Pilátová, M. B., \& Gönciová, G., 2016, Total synthesis and the anticancer activity of (+)spisulosine. Carbohydrate research, Vol. 435 : 26-36. doi https://doi.org/10.1016/j.carres.2016.09.010

He, F., Mai, L. H., Longeon, A., Copp, B. R., Loaëc, N., Bescond, A. \& Bourguet-Kondracki, M. L., 2015, Novel adociaquinone derivatives from the indonesian spons xestospongia sp. Marine drugs, Vol.13, No.5 : 2617-2628. doi : https://doi.org/10.3390/md13052617

Hudayah, T., Taib, M., Ismail, N., \& Muhammad, T. S. T., 2017, Methanol extracts of four selected marine sponss induce apoptosis in human breast cancer cell line, MCF-7. International Journal Of Research In Pharmaceutical Sciences, Vol.8, No.4 : 667-675.

Khalifa, S. A., Elias, N., Farag, M. A., Chen, L., Saeed, A., Hegazy, M. E. F. \& Chang, F. R., 2019, Marine natural products: a source of novel anticancer drugs. Marine Drugs, Vol.17, No.9 : $491 . \quad$ doi https://doi.org/10.3390/md17090491

Maiuthed, A., Pinkhien, T., Chamni, S., Suwanborirux, K., Saito, N., Petpiroon, N., \& Chanvorachote, P., 2017, Apoptosis-inducing effect of 
hydroquinone 5-o-cinnamoyl ester analog of renieramycin $\mathrm{m}$ on non-small cell lung cancer cells. Anticancer research, Vol.37, No.11 : 6259-6267.

Nazemi, M., Khaledi, M., Golshan, M., Ghorbani, M., Amiran, M. R., Darvishi, A., \& Rahmanian, O., 2020, Cytotoxicity activity and druggability studies of sigmasterol isolated from marine spons dysidea avara against oral epithelial cancer cell (KB/C152) and $\mathrm{T}$ lymphocytic leukemia cell line (jurkat/E6-1). Asian Pacific Journal of Cancer Prevention, Vol.21, No.4 : 997-1003. doi : 10.31557/APJCP.2020.21.4.997

Nguyen, H. M., Ito, T., Win, N. N., Vo, H. Q., Nguyen, H. T., \& Morita, H., 2019, A new sterol from the vietnamese marine spons xestospongia testudinaria and its biological activities. Natural Product Research, Vol.33, No.8 : 1175-1181. doi https://doi.org/10.1080/14786419.2018.146505 7

Petsri, K., Chamni, S., Suwanborirux, K., Saito, N., \& Chanvorachote, P., 2019, Renieramycin T induces lung cancer cell apoptosis by targeting Mcl-1 degradation: a new insight in the mechanism of action. Marine drugs, Vol.17, No.5 : 301. doi https://doi.org/10.3390/md17050301

Reddy, P. V., Hridhay, M., Nikhil, K., Khan, S., Jha, P. N., Shah, K., \& Kumar, D., 2018, Synthesis and investigations into the anticancer and antibacterial activity studies of $\beta$-carboline chalcones and their bromide salts. Bioorganic \& Medicinal Chemistry Letters, Vol.28, No.8 : 1278-1282. doi https://doi.org/10.1016/j.bmcl.2018.03.033

Ruocco, N., Costantini, S., \& Costantini, M., 2016, Blue-print autophagy: potential for cancer treatment. Marine Drugs, Vol.14, No.7 : 138. doi : https://doi.org/10.3390/md14070138

Sirimangkalakitti, N., Chamni, S., Charupant, K., Chanvorachote, P., Mori, N., Saito, N., \& Suwanborirux, K., 2016, Chemistry of renieramycins. 15 . synthesis of 22-o-ester derivatives of jorunnamycin a and their cytotoxicity against non-small-cell lung cancer Cells. Journal Of Natural Products, Vol.79, No.8 : 2089-2093. doi: https://doi.org/10.1021/acs.jnatprod.6b00433

Sirimangkalakitti, N., Chamni, S., Suwanborirux, K., \& Chanvorachote, P., 2017, Renieramycin M attenuates cancer stem cell-like phenotypes in
H460 lung cancer cells. Anticancer Research, Vol.37, No.2: 615-621.

Swantara, M. D., Rita, W. S., Suartha, N., dan Agustina, K. K., 2019, Anticancer activities of toxic isolate of xestospongia testudinaria spons. Veterinary World, Vol. 12, No.9 : 1434-1440.

Tun, J. O., Salvador-Reyes, L. A., Velarde, M. C., Saito, N., Suwanborirux, K., \& Concepcion, G. P., 2019, Synergistic cytotoxicity of renieramycin $\mathrm{M}$ and doxorubicin in MCF-7 breast cancer cells. Marine drugs, Vol.17, No.9 : 536. doi : https://doi.org/10.3390/md17090536

Trianto, A., Ridhlo, A., Triningsih, D. W., \& Tanaka, J., 2016, Study on anticancer activity of extracts of sponges collected from biak water, Indonesia. IOP Conf. Series: Earth and Environmental Science. Vol.55, No.1.

Wargasetia, T. L., \& Widodo, N., 2019, The link of marine products with autophagy-associated cell death in cancer cell. Current Pharmacology Reports, Vol.5, No.1 : 35-42. doi : https://doi.org/10.1007/s40495-01900167-8

Ye, J., Zhou, F., Al-Kareef, A. M., \& Wang, H., 2015, anticancer agents from marine spons. Journal Of Asian Natural Products Research, Vol.17, No.1 : 64-88. doi : https://doi.org/10.1080/10286020.2014.970535

Zhou, X., Yue, G. G. L., Tsui, S. K. W., Pu, J., Fung, K. P., \& Lau, C. B. S., 2018, Elaborating the role of natural products on the regulation of autophagy and their potentials in breast cancer therapy. Current Cancer Drug Targets, Vol.18, No.3 : 239-255. doi : https://doi.org/10.2174/1568009617666170330 124819 